\title{
Jacques Barrau, reconnu internationalement et méconnu de sa terre d'élection
}

\section{Georges Condominas}

\section{(2) OpenEdition \\ 1 Journals}

Édition électronique

URL : https://journals.openedition.org/jso/1355

DOI : $10.4000 /$ jso. 1355

ISSN : 1760-7256

Éditeur

Société des océanistes

\section{Édition imprimée}

Date de publication : 1 décembre 2002

Pagination : 13-14

ISSN : 0300-953x

\section{Référence électronique}

Georges Condominas, « Jacques Barrau, reconnu internationalement et méconnu de sa terre d'élection », Journal de la Société des Océanistes [En ligne], 114-115 | Année 2002, mis en ligne le 26 mai 2008, consulté le 28 juin 2022. URL : http://journals.openedition.org/jso/1355 ; DOI : https://doi.org/ $10.4000 /$ jso. 1355

\section{(c) (i) $\ominus$}

Journal de la société des océanistes est mis à disposition selon les termes de la Licence Creative Commons Attribution - Pas d'Utilisation Commerciale - Pas de Modification 4.0 International. 


\section{Jacques Barrau, reconnu internationalement et méconnu de sa terre d'élection}

par

\section{Georges CONDOMINAS *}

Lorsqu'enfin, après un demi-siècle, j'ai pris l'avion pour Nouméa, j'allais pouvoir revivre dans le concret l'enseignement de Maurice Leenhardt, les écrits, les propos d'André-Georges Haudricourt et de Jacques Barrau sur la Nouvelle-Calédonie et les environs. Curieusement, je me suis demandé alors quel type d'hommage les responsables du "Caillou » avaient rendu aux trois grands scientifiques qui, comme Jean-Marie Tjibaou - l'homme d'action avaient su révéler au monde la richesse humaine de ses habitants. Leurs noms avaient-ils été attribués à une avenue, une place, un monument ? En débarquant, j'eus beau consulter cartes et plans, je ne découvris qu'une petite rue Maurice Leenhardt, un point c'est tout! En dehors d'une dizaine de spécialistes, personne n'avait entendu prononcer le nom d'Haudricourt; quant à Barrau, il s'agissait seulement de l'entreprise coloniale d'import-export qui s'y était enrichie depuis un siècle. Les sujets sérieux de conversation portaient essentiellement sur le nickel, le lagon (les plongées, la voile et le surf)... En ce qui concerne la recherche scientifique, c'était suffisamment l'affaire de l'orstom et de la Commission du Pacifique Sud, mais on n'y touchait pas!!

Un jour, le directeur de l'orstom, qui avait initié un programme de recherche appliquée en collaboration avec des organismes locaux, voulut lancer l'affaire avec éclat en organisant un colloque qui attirerait l'attention de l'élite locale. Monsieur Jarrige me demanda de dire à cette occasion quelques mots sur les sciences humaines.
Ce qui devait n'être qu'une petite intervention inodore me donna l'occasion de réveiller les politiciens sur leurs responsabilités vis-à-vis de leurs concitoyens. Après avoir indiqué que Maurice Leenhardt était connu de certains d'entre eux au moins par les protestants car il était pasteur - , je fis remarquer qu'ils ignoraient tout d'Haudricourt alors que celui-ci avait jeté les bases d'une ethnohistoire multidisciplinaire qui auraient dû les intéresser. Je fus conduit tout naturellement à m'étendre plus particulièrement sur le cas de Jacques Barrau - un enfant du pays! - J'insistai sur le fait que lorsqu'une communauté produit un enfant de réputation internationale, et de l'envergure de celle de Jacques Barrau, cette communauté s'enorgueillit haut et fort (à tort ou à raison) d'avoir produit un tel sujet. Or, lorsque Jacques Barrau reçut le prix international Cosmos remis par l'empereur du Japon le 25 octobre 1994, y eut-il un écho grandiose en Nouvelle Calédonie ? Rien, à peine un petit chuchotement. Et pourtant, ce prix international, équivalent du Nobel, était attribué en grand apparat pour la seconde fois dans le monde et Jacques Barrau fut le premier Français à le recevoir. Imagine-t-on quelle aurait été l'attitude des responsables culturels et scientifiques d'une région métropolitaine qui aurait reçu un tel honneur?

Le point sur lequel j'insistai le plus dans ces périodes où l'on voyait se confronter les deux communautés calédoniennes était l'occasion où jamais de célébrer ensemble la promotion internationale de cet enfant du pays. En effet, Jacques Barrau m'avait dit à plusieurs reprises toute la

* Directeur d'Études à l'EHEss. Ce texte a été réalisé à partir d'un entretien enregistré par Florence Brunois. 
dette qu'il ressentait envers les paysans kanak qui lui avaient appris sur les plantes autant que les bons maîtres qu'il avait eu à l'université.

Je mis en avant un exemple de leur négligence : « la version française originelle de l'ouvrage écrit en collaboration avec Émile Massal, Plantes alimentaires du Pacifique Sud, édité en septembre 1956, réimprimé en 1975, est aujourd'hui épuisée et ce, depuis quelques années. Or, paradoxalement la traduction anglaise se trouve aisément et dans une impression de meilleure qualité ». Je suggérai alors que le Territoire soutienne dans les meilleurs délais la réédition de la version française par la Commission du Pacifique Sud et que des exemplaires de cette version soient distribués dans toutes les écoles, en priorité celles de l'intérieur. Ainsi, tous les enfants pourraient être informés sur les plantes alimentaires et les techniques horticoles de leur pays. Les enfants kanak, surtout ceux vivant en brousse, disposeraient d'un ouvrage qui, tout en les intéressant, consoliderait leur connaissance de la langue française. Une annexe dans laquelle, pour chaque plante étudiée, serait donné le terme dans chacune des principales langues kanak viendrait compléter cet ouvrage...

Rien n'a été fait jusqu'à présent ! 